\title{
Design and development of feasibility analysis software for live working
}

\author{
*Guo Hao ${ }^{1,2,3}$, Wang Zhigang ${ }^{1,2,3}$, Mao dun ${ }^{1,2,3}$, Qiaomingming ${ }^{1,2,3}$, Zhen zhaohui ${ }^{1,2,3}$ \\ ${ }^{1}$ State Grid Hunan Transmission \& Maintenance Company, Hengyang, China 421000; \\ 2. Intelligent Live Working Technology and Equipment Key Laboratory of Hunan Province(2016TP1025) Changsha, China 410000; \\ ${ }^{3}$ Live Inspection and Intelligent Operation Technolgoy State Grid Corporation Laboratory 410100
}

\begin{abstract}
The work load of the traditional calculation method of safety distance check and circuit mechanics calculation is huge inefficiency, this paper presents a set of software of safety analysis and mechanics calculation for live working, the electrical and mechanical parameters of live working transmission lines are obtained, the feasibility of operation is analyzed, working tools are reasonably selected to improve the safety and efficiency of live working, it is of great significance to reduce the emergency response time, the electric safety distance check and the line mechanics calculation methods.
\end{abstract}

\section{Introduction}

In the power system, live working is a special discipline with "high risk, high altitude, high voltage and high technology". Live working personnel need to complete multiple tasks in a strong electric field, such as replacing insulators and fittings, repairing conductor and ground wire, eliminating defects of wire fittings, removing foreign matters and handling drainage plate heat. Hence, engineering technicians engaging in live working should have the knowledge of electricity and mechanics. Prior to working, technicians should carry out electrical safety distance check and circuit mechanics calculation according to the situation of field operation to demonstrate the feasibility and form an operation plan for work guidance. However, the approximation and complexity of the traditional calculation method may lead to errors in the calculation results. The conductor force (the vertical gravity or the horizontal tension) is not estimated accurately, and the tonnage of tools selected according to the calculation results is too large or too small, which increases the workload of operators or causes conductor disconnection, grounding, short circuit and other malignant safety accidents seriously endangering the safety of human life and power $\operatorname{grid}^{[1]}$. Meanwhile, the heavy workload of the traditional calculation method seriously affects the working efficiency. In case of urgent repair work, it extends the emergency response time $e^{[2-5]}$. Besides, only some technicians grasp the methods of electrical safety distance check for living working of the transmission line and the circuit mechanics calculation, while most workers engaging in live working fail to know relevant knowledge, and it is hard for them to make up in a short time.
Therefore, developing a set of simple and accurate software of safety analysis and mechanics calculation for live working is very significant for obtaining electrical and mechanical parameters of live working line of the transmission line, analyzing the operation feasibility, rationally choosing operation tools, improving living working safety and working efficiency, shortening emergency response time and promoting the methods of electrical safety distance check and circuit mechanics calculation among the numerous living working personnel.

\section{Software function and principle}

\subsection{Mechanics check}

The calculation was conducted in a fine day, without ice and the wind speed of no more than Level 5. Thus, during relevant calculation, the dead weight of the conductor and fittings, and the load resulting from wind pressure were only considered.

(1) Dead weight load of conductor $\left(g_{1}\right)$

$$
g_{1}=\frac{G_{0}}{S}
$$

Wherein, G0 - conductor weight per meter $(\mathrm{kg} / \mathrm{km})$; S - all sectional area of conductor (mm2).

(2) Specific load of wind pressure

The wind pressure over the conductor is caused by the kinetic energy of air. The horizontal wind pressure in the direction of the vertical line is:

$$
P=\alpha K F \frac{V^{2}}{16} \sin ^{2} \theta(9.8 \mathrm{~N})
$$

\footnotetext{
* Corresponding author: 819546574@qq.com
} 
Wherein, $\alpha$ - nonuniform coefficient of wind speed, 1.0; V - wind speed, $10 \mathrm{~m} / \mathrm{s} ; \mathrm{F}$ - Projection plane of wind surface on the plane vertical to the wind direction; $\theta$ Horizontal angle between wind direction and wind projection plane. During the calculation, it was assumed that the wind direction is perpendicular to the direction of the power line, $\sin 2 \theta=1$.

$\mathrm{K}$ - Dynamic coefficient of air, 1.1.

(3) Comprehensive specific load

$g_{6}=\sqrt{g_{1}^{2}+g_{4}^{2}}$

(4) Vertical load on the insulator string:

$$
Q=g_{1} S l_{\mathrm{z}}+W
$$

Wherein, W - Including the weight of spacer, pulling plate, cable clamp and equipotential operators, approximately $200 \mathrm{~kg}$ (compound insulator weight is not considered; $\pm 800 \mathrm{kV}$ UHV transmission line is a six divided conductor).

(5) Horizontal load on the insulator string:

$$
P=g_{4} S l_{\mathrm{p}}
$$

(6) Total load on the insulator string:

$$
G=\sqrt{Q^{2}+P^{2}}
$$

(7) Total load on the single subconductor

$$
G_{l}=G / n
$$

Wherein, $\mathrm{n}$ is the number of divided conductors, unit: pes.

\subsection{Stress calculation and analysis of tension insulator replacement}

It is assumed that under known meteorological conditions, the temperature, specific load and stress are $\mathrm{tm}$, gm and $\sigma \mathrm{m}$ respectively. We set the temperature,

specific load and stress to th, $g_{\mathrm{n}}$ and $\sigma \mathrm{n}$ respectively under the meteorological conditions. Then, the conductor state equation is:

$$
\sigma_{\mathrm{n}}-\frac{g_{\mathrm{n}}^{2} l^{2}}{24 \beta \sigma_{\mathrm{n}}^{2}}=\sigma_{\mathrm{m}}-\frac{g_{\mathrm{m}}^{2} l^{2}}{24 \beta \sigma_{\mathrm{m}}^{2}}-\frac{\alpha}{\beta}\left(t_{\mathrm{n}}-t_{\mathrm{m}}\right)
$$

The stress of tension insulator is $\mathrm{T}=\sigma \mathrm{n} \times \mathrm{S}$

Wherein, $\alpha$ - Thermal expansion coefficient of conductor; $\beta$ - Elastic elongation coefficient of conductor, $154 \times 10-6(\mathrm{~mm} 2 / 9.8 \mathrm{~N}) ; 1-\operatorname{Span}(\mathrm{m})$.

\subsection{Stress during handling conductor and ground wire breaking}

According to the conductor stress, specific load and air temperature before the rope ladder is suspended, the following state equation is used to calculate the conductor stress after the rope ladder is suspended ${ }^{[3-4]}$ :

$\sigma_{2}-\frac{g^{2} l_{D}^{2} E}{24 \sigma_{2}^{2}}-\frac{l_{x} Q^{\prime}\left(Q^{\prime}+l_{x} s g\right) E}{8 s^{2} \sigma_{2}^{2} \sum \frac{l_{i}}{\cos \phi}}=\sigma_{1}-\frac{l_{D}^{2} g^{2} E}{24 \sigma_{1}^{2}}-\alpha E\left(t_{2}-t_{1}\right) \quad$ The

sag of ground wire for which the rope ladder is suspended in the continuous gear can be figured out according to the following equation:

$$
f_{x}=\frac{x\left(l_{x}-x\right) g}{2 \sigma_{2} \cos \varphi_{x}}+\frac{x\left(l_{x}-x\right) Q}{l_{x} \sigma_{2} s \cos ^{2} \varphi_{x}}
$$

\subsection{Safety distance check}

Safety distance refers to the minimum air distance that should be maintained between ground potential operators and the charged body or between equipotential operators and the grounding body in order to ensure personal safety. Safety distance of live working is the key to ensure the safety of people and equipment in live working. The principle of determining the safety distance is to ensure that the maximum possible overvoltage does not cause equipment insulation flashover or air gap discharge. The basic principle of determining the minimum safety distance is to increase a reasonable increment of human activity based on the minimum electrical clearance distance. Generally, the increment can be $0.5 \mathrm{~m}$. The minimum combined clearance refers to the sum of the distance between the human body and the grounding body and the distance between the human body and the charged body when the operator in the clearance is in the position of the minimum $50 \%$ of operating impulsive discharge voltage. The main classification of safety distance is as below: (1) safety distance of ground potential: minimum distance that should be maintained between the ground potential operator and the charged body. (2) Equipotential safety distance: minimum distance that should be maintained between the equipotential operator on the charged body and the surrounding grounding body. (3) Minimum interphase distance: minimum distance that should be maintained between the equipotential operator on the charged body and the neighbor-phase charged body. (4) Combined clearance: the sum of the distance between the human body and the grounding body and the distance between the human body and the charged body during operator's entry in the electric field.

The hazard index of live working should be first calculated during determining the safety distance. The hazard index of live working is the basis of determining key technical parameters of live working. Its calculation is based on the statistical method recommended by IEC and combined with the overvoltage level of live working and clearance test results. After the elevation correction, the minimum safety distance for live working, the minimum combined clearance and the minimum effective insulation length of insulating tools are finally determined on the premise of ensuring the risk index of live working $<10-5$. Table 1 shows safety distance values of live working of typical UHV DC transmission lines.

Different ways can be chosen to enter the electric field according to different operation methods. In accordance with the provisions of Power Safety Working Rules of State Grid Corporation - Line (Q/GDW1799.2-2013), at $\pm 800 \mathrm{kv}$, the safety distance between the operator and the charged body shall not be less than $6.8 \mathrm{~m}$ in the process of live working. The safety distance between the equipotential operator and the 
grounding body shall not be less than $6.8 \mathrm{~m}$. The combined clearance of the operator shall not be less than $6.6 \mathrm{~m}$ in the process of entering the electric field. Hence, it is necessary to calculate and check the safety distance and combined clearance in different operation methods, and live working cannot be conducted before the requirements are $\operatorname{met}^{[2-3]}$.

\section{Interface of calculation interface}

According to the calculation principle and calculation process, the calculation software was prepared and the design function interfaces are as below.

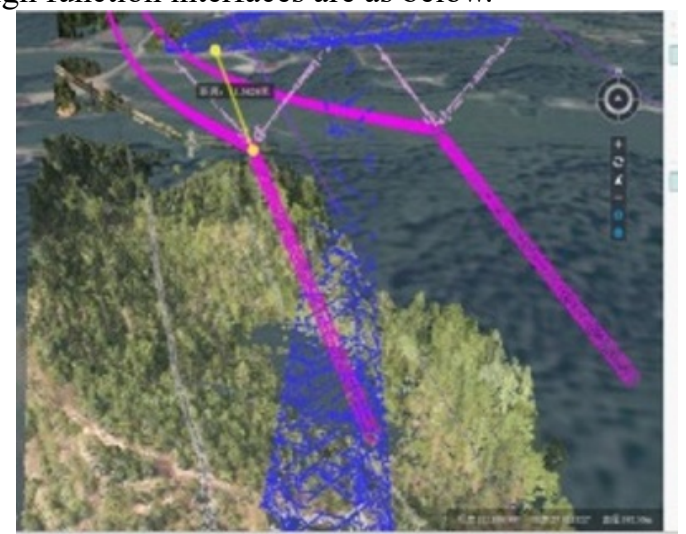

Fig.1 Ground potential safety distance check

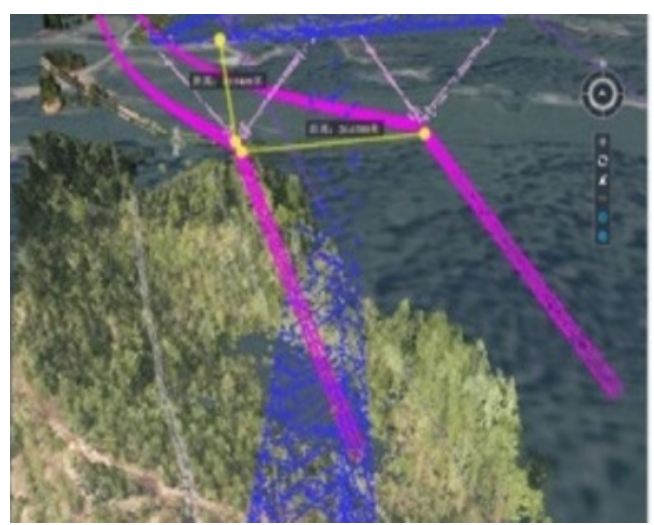

Fig.2 Interphase distance check

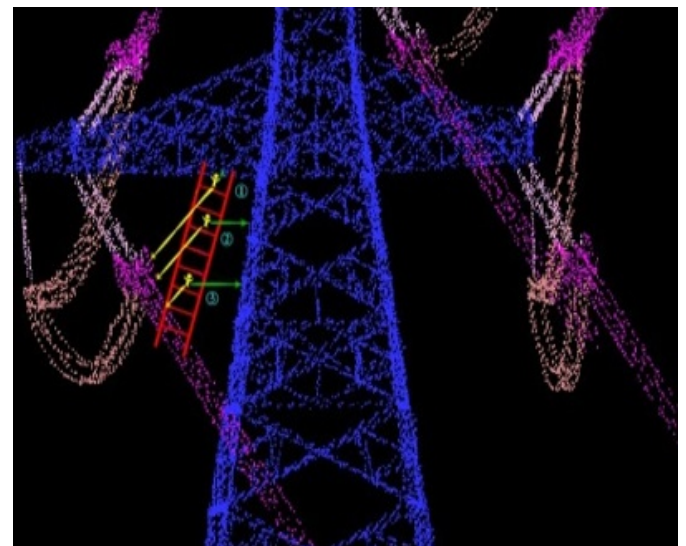

Fig.3 Interface of electric field entry with horizontal ladder method

\section{Application example}

A straight tower of a $\pm 800 \mathrm{kV}$ line is located in Xuetangshan Village, Niutian Town, Taojiang County, Yiyang City, where the terrain is mountainous. The tower model is Z27154A-54, and the distance between the ground and the minimum hanging line of the pole is $54 \mathrm{~m}$, with the front span of $650 \mathrm{~m}$, rear span of $377 \mathrm{~m}$ and vertical span of $628 \mathrm{~m}$.

No.4374 tension tower of $\pm 800 \mathrm{kV}$ Qishao Line is located in Daoyuanchong Village, Niutian Town, Taojiang County, Yiyang Citywhere the terrain is mountainous. The tower model is J27151A-39 and the distance between the ground and the minimum hanging line of the pole is $39 \mathrm{~m}$, with the overall height of $54 \mathrm{~m}$ and corner angle of $0^{\circ}$. It is necessary to enter equipotential for defect removal. The hanging basket method was used for the operation, and the conductor model is $6 \times \mathrm{JL} 1 / \mathrm{G} 2 \mathrm{~A} \sim 1250 / 100$ aluminum conductor with steel core. The insulator model is FXBZ- $\pm 800 / 550-2$, and the code of the insulator fitting string is $8 \mathrm{~V} 2 \mathrm{~S}-5065-55 \mathrm{H}-2 \mathrm{~A} 2-\mathrm{T}$. The line parameters are shown in the following table.

Table 1 Tower parameter list

\begin{tabular}{|c|c|c|c|c|c|}
\hline $\begin{array}{c}\text { Conduct } \\
\text { or } \\
\text { model }\end{array}$ & $\begin{array}{c}\text { Computed } \\
\text { sectional } \\
\text { area }\left(\mathrm{mm}^{2}\right)\end{array}$ & $\begin{array}{c}\text { Computed } \\
\text { weight } \\
(\mathrm{kg} / \mathrm{km})\end{array}$ & $\begin{array}{c}\text { Front } \\
\text { span } \\
(\mathrm{m})\end{array}$ & $\begin{array}{c}\text { Rear } \\
\text { span } \\
(\mathrm{m})\end{array}$ & $\begin{array}{c}\text { Vertical } \\
\text { span } \\
(\mathrm{m})\end{array}$ \\
\hline $\begin{array}{c}\mathrm{JL} 1 / \mathrm{G} 2 \\
\mathrm{~A}-1250 / \\
100\end{array}$ & 1350.03 & 4252.3 & 650 & 377 & 628 \\
\hline
\end{tabular}

Setting-out stress table:

According to the tower list, the representative span of \#4374 tension tower is $531 \mathrm{~m}$, and the conductor is divided into six. The insulators are made in four strings. The representative span is $500 \mathrm{~m}$ according to the setting-out stress table, and the temperature is $15^{\circ} \mathrm{C}$ (temperature $15^{\circ} \mathrm{C} \sim 25^{\circ} \mathrm{C}$, representative span $500 \mathrm{~m}-550 \mathrm{~m}$, temperature $15^{\circ} \mathrm{C}$, representative span $500 \mathrm{~m}$, the horizontal stress of the conductor is maximum).

The software is used to analyze the feasibility of live working.

(1) Safety distance analysis

The corresponding point cloud data can be found through operating the software to determine the ground potential position and equipotential position. 


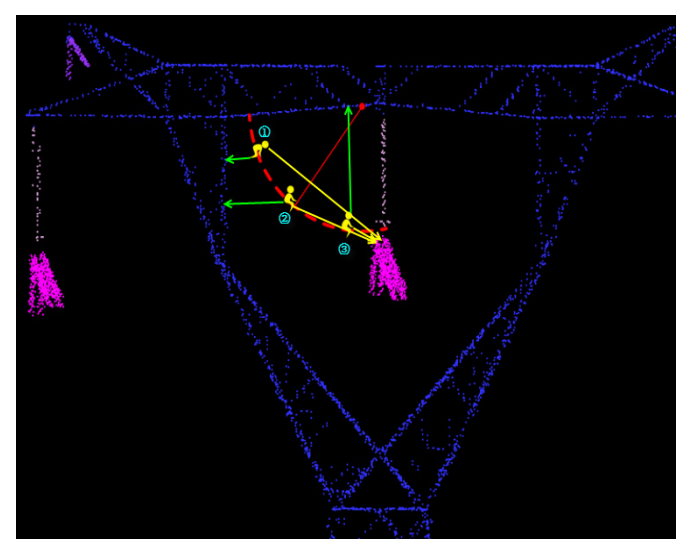

Fig.4 Entering the electric field with hanging basket method for checking

(2) Mechanics check

Input parameters and click calculation to figure out the tower stress.

(3) Production analysis report

Table2 Safety distance calculation results

\begin{tabular}{|c|c|c|c|c|}
\hline SN & $\begin{array}{c}\text { Safety } \\
\text { distance type } \\
1\end{array}$ & $\begin{array}{c}\text { Safety } \\
\text { distance } \\
\text { value } \\
(\mathrm{mm})\end{array}$ & $\begin{array}{c}\text { Required value } \\
\text { in Safety } \\
\text { Specifications } \\
\text { (mm) }\end{array}$ & Conclusion \\
\hline $\begin{array}{c}\text { Safety } \\
\text { distance of } \\
\text { ground } \\
\text { potential }\end{array}$ & 12240 & 6800 & $\begin{array}{c}\text { Meet } \\
\text { requirements }\end{array}$ \\
\hline 2 & $\begin{array}{c}\text { Equipotentia } \\
\text { 1 safety } \\
\text { distance }\end{array}$ & 12240 & 6800 & $\begin{array}{c}\text { Meet } \\
\text { requirements }\end{array}$ \\
\hline 3 & $\begin{array}{c}\text { Minimum } \\
\text { interphase } \\
\text { distance }\end{array}$ & 36576 & 72000 & $\begin{array}{c}\text { Meet } \\
\text { requirements }\end{array}$ \\
\hline 4 & $\begin{array}{c}\text { Combined } \\
\text { clearance }\end{array}$ & 15843 & 6600 & $\begin{array}{c}\text { Meet } \\
\text { requirements }\end{array}$ \\
\hline
\end{tabular}

\section{Conclusions}

(1) Safety distance of ground potential: the minimum distance that should be maintained between the ground potential operator and the charged body is $12240 \mathrm{~mm}$.

(2) Equipotential safety distance: the minimum distance that should be maintained between the equipotential operator on the charged body and the surrounding grounding body is $12240 \mathrm{~mm}$.

(3) Minimum interphase distance: the minimum distance that should be maintained between the equipotential operator on the charged body and the neighbor-phase charged body is about $36576 \mathrm{~mm}$.

(4) Combined clearance: the minimum combined clearance during operator's entry in the electric field is $15843 \mathrm{~mm}$.

Through the calculation, the safety distance and combined clearance meet the requirements, so the operation can be conducted.

Through the calculation, the total load of the insulator string on the tower is $156988.2 \mathrm{~N}$, so it is recommended to choose the tools with the rated load greater than the total load.

\section{References}

1. Hu Yi, Liu Kai. Live working of UHV AC/DC transmission lines [M]. Beijing: China Electric Power Press, 2011.

2. Power Safety Working Rules of State Grid Corporation - Line (Q/GDW 1799.2-2013) [S]. 2013.

3. Technical Specification for Live Working of $\pm 800 \mathrm{KV}$ DC lines (DL/T 1242-2013) [S].

4. Li Ruhu. Practical mechanics of Live Working [J]. China Southern Power Grid Technology [M]. 2009,3 (2): 77-80.

5. SHU Yinbiao,HU Yi,LI Xue. Maintenance and live working technology for ultra high voltage transmission line[J]. High Voltage Engineering, 2007, 33(6):1-5. 